Pacific Journal of Mathematics

A GENERALIZATION OF A THEOREM OF F. RIESZ 


\title{
A GENERALIZATION OF A THEOREM OF F. RIESZ
}

\section{Frank N. HugGins}

\begin{abstract}
In this paper, the concept of bounded slope variation, that of the derivative of a function with respect to an increasing function, and the Lane integral are used to obtain a generalization of a theorem of Frédéric Riesz.
\end{abstract}

In [3], R. E. Lane defined an integral which is an extension of the Stieltjes mean sigma integral defined by H. L. Smith [5]. If each of $f$ and $g$ is a real-valued function whose domain includes $[a, b]$ and $D=\left\{x_{i}\right\}_{i=0}^{n}$ is a subdivision of $[a, b]$, then $S_{D}(f, g)$ denotes the sum

$$
\sum_{i=1}^{n} \frac{1}{2}\left[f\left(x_{i}\right)+f\left(x_{i-1}\right)\right]\left[g\left(x_{i}\right)-g\left(x_{i-1}\right)\right] \text {. }
$$

The concepts of singular graph, exceptional number and summability set are as in [3]. If each of $f$ and $g$ is a real-valued function whose domain includes $[a, b]$ and if there exists a summability set $G$ for $f$ and $g$ in $[a, b]$, then the Lane integral $\int_{a}^{b} f d g$ is the refinement limit

$$
\operatorname{limit}_{D \subset G} S_{D}(f, g) \text {. }
$$

In case the entire interval $[a, b]$ is a summability set for $f$ and $g$ in $[a, b]$, the Lane integral $\int_{a}^{b} f d g$ is the Stieltjes mean sigma integral $M \int_{a}^{b} f d g$.

By Theorem 4.1 of [2], if $f$ is quasicontinuous on $[a, b]$ and $g$ is of bounded variation on $[a, b]$, then $\int_{a}^{b} f d g$ exists. (A function $f$ is said to be quasicontinuous at $(c, f(c))$ if both $f(c+)$ and $f(c-)$ exist.)

DEFINITION 1. The statement that $f$ has bounded slope variation with respect to $m$ over $[a, b]$ means that $f$ is a function whose domain includes $[a, b], m$ is a real-valued increasing function on $[a, b]$, and there exists a nonnegative number $B$ such that if $\left\{x_{i}\right\}_{i=0}^{n}$ is a subdivision of $[a, b]$ with $n>1$, then

$$
\sum_{i=1}^{n-1}\left|\frac{f\left(x_{i+1}\right)-f\left(x_{i}\right)}{m\left(x_{i+1}\right)-m\left(x_{i}\right)}-\frac{f\left(x_{i}\right)-f\left(x_{i-1}\right)}{m\left(x_{i}\right)-m\left(x_{i-1}\right)}\right| \leqq B .
$$

The least such number $B$ is called the slope variation of $f$ with respect to $m$ over $[a, b]$ and is denoted by $V_{a}^{b}(d f / d m)$. [Note: $V_{a}^{a}(d f / d m)=0$.]

The above sum is nondecreasing with respect to refinements. In [4], F. Riesz proved that a necessary and sufficient condition 
that a function $F$ defined on the interval $[a, b]$ be the integral of a function of bounded variation on $[a, b]$ is that $F$ have bounded slope variation with respect to $I$ over $[a, b]$, where $I$ is the function defined, for each $x$, by $I(x)=x$. In this paper, Riesz's result will be generalized using the Lane integral instead of the Riemann integral.

By Lemma 3.3 of [6], if $f$ has bounded slope variation with respect to $m$ over $[a, b]$ and $a \leqq c<b$, then

$$
D_{m}^{+} f(c)=\lim _{x \rightarrow c^{+}} \frac{f(x)-f(c)}{m(x)-m(c)}
$$

exists and if $a<c \leqq b$,

$$
D_{m}^{-} f(c)=\lim _{x \rightarrow c^{-}} \frac{f(x)-f(c)}{m(x)-m(c)}
$$

exists.

LEMma 1. If $f$ has bounded slope variation with respect to $m$ over $[a, b], c$ is a number in $[a, b]$, and $m$ is continuous on the right (left) at $(c, m(c))$, then $f$ is continuous on the right (left) at $(c, f(c))$.

Proof. Let $\varepsilon$ denote a positive number and let $c$ be a number in $[a, b]$. Suppose $m$ is continuous on the right at $(c, m(c))$. Then $a \leqq c<b$ and $D_{m}^{+} f(c)$ exists. Therefore there exists a positive number $\delta_{1}$ such that if $c<x<c+\delta_{1}$, then

$$
\left|\frac{f(x)-f(c)}{m(x)-m(c)}-D_{m}^{+} f(c)\right|<1
$$

from which it follows that

$$
|f(x)-f(c)|<\left[\left|D_{m}^{+} f(c)\right|+1\right]|m(x)-m(c)| \text {. }
$$

Since $m$ is continuous on the right at $(c, m(c))$, there exists a positive number $\delta_{2}$ such that if $c<x<c+\delta_{2}$, then $|m(x)-m(c)|<\varepsilon /\left[\left|D_{m}^{+} f(c)\right|+1\right]$. Let $\delta=\min .\left[\delta_{1}, \delta_{2}\right]$. Then if $c<x<c+\delta$,

$$
\begin{aligned}
|f(x)-f(c)| & <\left[\left|D_{m}^{+} f(c)\right|+1\right]|m(x)-m(c)| \\
& <\left[\left|D_{m}^{+} f(c)\right|+1\right] \cdot \varepsilon /\left[\left|D_{m}^{+} f(c)\right|+1\right] \\
& =\varepsilon .
\end{aligned}
$$

Therefore $f$ is continuous on the right at $(c, f(c))$.

If $m$ is continuous on the left at $(c, m(c))$, a similar argument will show that $f$ is continuous on the left at $(c, f(c))$.

Definition 2. Suppose $m$ is an increasing function on $[a, b], f$ is 
a function whose domain includes $[a, b]$ and $c$ is a number in $[a, b]$. The statement that $f$ has a derivative with respect to $m$ at the point $(c, f(c))$ means that

$$
D_{m} f(c)=\lim _{x \rightarrow c} \frac{f(x)-f(c)}{m(x)-m(c)}
$$

exists.

THEOREM 1. If $f$ has bounded slope variation with respect to $m$ over $[a, b]$, then $D_{m} f(x)$ exists for each $x$ in $[a, b]-E$, where $E$ is a countable set.

Proof. Since $f$ has bounded slope variation with respect to $m$ over $[a, b], D_{m}^{+} f(x)$ exists for each $x$ in $[a, b)$ and $D_{m}^{-} f(x)$ exists for each $x$ in $(a, b]$. Let $E_{1}$ denote the set of all numbers $x$ in $[a, b]$ such that $D_{m}^{-} f(x)<D_{m}^{+} f(x)$ and let $E_{2}$ denote the set of all number $x$ in $[a, b]$ such that $D_{m}^{-} f(x)>D_{m}^{+} f(x)$. Let all rational numbers be arranged in a sequence $r_{1}, r_{2}, r_{3}, \cdots$. Then if $c$ is a number in $E_{1}$ there is a smallest positive integer $k$ such that

$$
D_{m}^{-} f(c)<r_{k}<D_{m}^{+} f(c) .
$$

There is a smallest positive integer $h$ such that $r_{h}<c$ and

$$
\frac{f(x)-f(c)}{m(x)-m(c)}<r_{k}
$$

for $r_{h}<x<c$ and a smallest positive integer $n$ such that $r_{n}>c$ and

$$
\frac{f(x)-f(c)}{m(x)-m(c)}>r_{k}
$$

for $c<x<r_{n}$. These two inequalities together give

$$
f(x)-f(c)>r_{k}[m(x)-m(c)]
$$

for $r_{h}<x<r_{n}, x \neq c$. Thus to every number $c$ in $E_{1}$ there corresponds a unique triad $(h, k, n)$ of positive integers. Suppose some two numbers $x_{1}$ and $x_{2}$ of $E_{1}$ correspond to the same triad $(h, k, n)$. Then, on putting $c=x_{1}$ and $x=x_{2}$ in (1), we have

$$
f\left(x_{2}\right)-f\left(x_{1}\right)>r_{k}\left[m\left(x_{2}\right)-m\left(x_{1}\right)\right]
$$

and, on putting $c=x_{2}$ and $x=x_{1}$,

$$
f\left(x_{1}\right)-f\left(x_{2}\right)>r_{k}\left[m\left(x_{1}\right)-m\left(x_{2}\right)\right]
$$

or 


$$
f\left(x_{2}\right)-f\left(x_{1}\right)<r_{k}\left[m\left(x_{2}\right)-m\left(x_{1}\right)\right] .
$$

This involves a contradiction. Therefore no two numbers of $E_{1}$ correspond to the same triad. Since the set of triads of positive integers is countable, it follows that $E_{1}$ is countable. A similar argument will show that $E_{2}$ is countable. Therefore $E=E_{1} \cup E_{2}$ is countable.

THEOREM 2. If the function $m$ is increasing on $[a, b]$, each of the functions $f$ and $g$ is continuous on $[a, b]$ and $D_{m} f(x)=D_{m} g(x)$ for each $x$ in $[a, b]-H$, where $H$ is a countable set, then $f(x)=g(x)-$ $g(a)+f(a)$ for each $x$ in $[a, b]$.

Proof. Let $F$ be the function defined, for each $x$ in $[a, b]$, by $F(x)=f(x)-g(x)$. Then $F$ is continuous on $[a, b]$ and $D_{m} F(x)=0$ for each $x$ in $[a, b]-H$. Let $\varepsilon$ denote a positive number and let $c$ be a number in $(a, b]$. Let $H \cap[a, c]=\left\{p_{1}, p_{2}, \cdots, p_{n}, \cdots\right\}$. Since $F$ is continuous on $[a, b]$, for each positive integer $n$ there exists a positive number $\delta_{n}$ such that if $x$ is in $\left(p_{n}-\delta_{n}, p_{n}+\delta_{n}\right) \cap[a, c]$, then

$$
\left|F(x)-F\left(p_{n}\right)\right|<\varepsilon / 2^{n+2} \text {. }
$$

Let $h_{n}=\left(p_{n}-\delta_{n}, p_{n}+\delta_{n}\right)$. It follows that if $x_{1}$ and $x_{2}$ are numbers in $h_{n} \cap[a, c]$, then

$$
\left|F\left(x_{1}\right)-F\left(x_{2}\right)\right|<\varepsilon / 2^{n+1} .
$$

For each $n$, choose some particular $h_{n}$ satisfying the above conditions. Now consider any number $t$ in $[a, c]-H \cap[a, c]$. Then $D_{m} F(t)=0$. If $t$ is in $(a, c)$, there is a positive number $\delta_{t}$ such that $\left(t-\delta_{t}, t+\delta_{t}\right)$ is a subset of $(a, c)$ and if $x$ is in $\left(t-\delta_{t}, t+\delta_{t}\right)$ and $x \neq t$, then

$$
\left|\frac{F(x)-F(t)}{m(x)-m(t)}\right|<\frac{\varepsilon}{12[m(c)-m(a)]}
$$

or

$$
|F(x)-F(t)|<\frac{\varepsilon|m(x)-m(t)|}{12[m(c)-m(a)]}<\frac{\varepsilon \cdot V(t)}{12[m(c)-m(a)]}
$$

where $V(t)$ is the variation of $m$ over $\left[t-\delta_{t}, t+\delta_{t}\right]$. If $t=a$, there exists a positive number $\delta_{a}$ such that if $x \neq a$ and $x$ is in $\left(a-\delta_{a}, a+\delta_{a}\right) \cap$ $[a, c]$, then

$$
|F(x)-F(a)|<\frac{\varepsilon \cdot V(a)}{12[m(c)-m(a)]}
$$

where $V(a)$ is the variation of $m$ over $\left[a, a+\delta_{a}\right]$. If $t=c$, there exists 
a positive number $\delta_{c}$ such that if $x \neq c$ and $x$ is in $\left(c-\delta_{c}, c+\delta_{c}\right) \cap$ $[a, c]$, then

$$
|F(x)-F(c)|<\frac{\varepsilon \cdot V(c)}{12[m(c)-m(a)]}
$$

where $V(c)$ is the variation of $m$ over $\left[c-\delta_{c}, c\right]$. It follows that if $t$ is in $[a, c]-H \cap[a, c]$ and $x_{1}$ and $x_{2}$ are numbers in $\left(t-\delta_{t}, t+\delta_{t}\right) \cap$ $[a, c]$, then

$$
\left|F\left(x_{1}\right)-F\left(x_{2}\right)\right|<\frac{\varepsilon \cdot V(t)}{6[m(c)-m(a)]} .
$$

Let $g_{t}=\left(t-\delta_{t}, t+\delta_{t}\right)$. For each $t$ in $[a, c]-H \cap[a, c]$, choose some particular $g_{t}$ satisfying the above conditions. Let $G$ denote the collection to which $g$ belongs if and only if either (1) for some positive integer $n, g=h_{n}$ or (2) for some $t$ in $[a, c]-H \cap[a, c], g=g_{t}$. $\quad G$ is a collection of open intervals covering $[a, c]$, hence there exists a finite subcollection $G^{\prime}$ of $G$ that covers $[a, c]$. Choose a finite chain $\left\{R_{1}, R_{2}, \cdots, R_{k}\right\}$ of intervals of $G^{\prime}$ covering $[a, c]$ and having the property that if $R_{i} \cap$ $R_{j} \neq \varnothing$, then $|i-j|=1$. Let $a=x_{0}, x_{1}$ be a number in $R_{1} \cap R_{2}, x_{2}$ be a number in $R_{2} \cap R_{3}, \cdots, x_{k-1}$ be a number in $R_{k-1} \cap R_{k}$, and $x_{k}=c$. Note that if for every $i \leqq k, R_{i}$ is $g_{t}$ for some $t$ in $[a, c]-H \cap[a, c]$ and $V_{i}=V(t)$ for that $t$, then

$$
\sum_{i=1}^{k} V_{i}<3[m(c)-m(a)] .
$$

Now

$$
F(c)-F(\alpha)=\sum_{i=1}^{k}\left[F\left(x_{i}\right)-F\left(x_{i-1}\right)\right] .
$$

Therefore

$$
\begin{aligned}
|F(c)-F(a)| \leqq & \sum_{i=1}^{k}\left|F\left(x_{i}\right)-F\left(x_{i-1}\right)\right| \\
= & \sum_{1}\left|F\left(x_{i}\right)-F\left(x_{i-1}\right)\right| \\
& +\sum_{2}\left|F\left(x_{i}\right)-F\left(x_{i-1}\right)\right|
\end{aligned}
$$

where the first sum is the sum of those terms for which $R_{i}$ is some $h_{n}$ and the second sum is the sum of those terms for which $R_{i}$ is some $g_{t}$. Now $x_{i-1}$ and $x_{i}$ are in $R_{i}$ so that

$$
\left|F\left(x_{i}\right)-F\left(x_{i-1}\right)\right|<\left\{\begin{array}{l}
\varepsilon / 2^{n+1} \text { if } R_{i}=h_{n} \\
\frac{\varepsilon \cdot V(t)}{6[m(c)-m(a)]} \text { if } R_{i}=g_{t} .
\end{array}\right.
$$


Hence

$$
\sum_{1}\left|F\left(x_{i}\right)-F\left(x_{i-1}\right)\right|<\sum_{n=1}^{\infty} \varepsilon / 2^{n+1}=\varepsilon / 2
$$

and

$$
\begin{aligned}
\sum_{2}\left|F\left(x_{i}\right)-F\left(x_{i-1}\right)\right| & <\frac{\varepsilon}{6[m(c)-m(a)]} \sum_{i=1}^{k} V_{i} \\
& <\frac{\varepsilon \cdot 3[m(c)-m(a)]}{6[m(c)-m(a)]}=\frac{\varepsilon}{2} .
\end{aligned}
$$

Therefore $|F(c)-F(a)|<\varepsilon / 2+\varepsilon / 2=\varepsilon$. Thus $F(c)=F(a)$. But $c$ was any number in $(a, b]$. Hence for each $x$ in $[a, b], F(x)=F(a)$ or $f(x)=g(x)-g(a)+f(a)$.

THEOREM 3. In order that the function $F$ defined on $[a, b]$ be the Lane integral of a function $f$ of bounded variation on $[a, b]$ with respect to a continuous, increasing function $m$ on $[a, b]$, it is necessary and sufficient that $F$ have bounded slope variation with respect to $m$ over $[a, b]$.

Proof. It is easy to see that the condition is necessary. Suppose that $F$ has bounded slope variation with respect to $m$ over $[a, b]$. Then $F$ is continuous on $[a, b]$. Let $f$ be the function defined, for each $x$ in $[a, b]$, by

$$
\left\{\begin{array}{l}
f(x)=D_{m}^{+} F(x) \text { for each } x \text { in }[a, b) \\
f(b)=D_{m}^{-} F(b) .
\end{array}\right.
$$

Then $f$ is of bounded variation on $[a, b]$ and is therefore quasicontinuons on $[a, b]$. Moreover, $D_{m} F(x)=f(x)$ for each $x$ in $[a, b]-E$, where $E$ is a countable set. Let $G$ be the function defined, for each $x$ in $[a, b]$, by $G(x)=\int_{a}^{x} f d m$. Then $G$ is continuous on $[a, b]$ and $D_{m} G(x)=f(x)$ at each number $x$ in $[a, b]$ such that $f$ is continuous at $(x, f(x))$. Since $f$ is quasicontinuous on $[a, b], D_{m} G(x)=f(x)$ for each $x$ in $[a, b]-K$, where $K$ is a countable set. Therefore $D_{m} F(x)=$ $D_{m} G(x)$ for each $x$ in $[a, b]-H$, where $H$ is a subset of $E \cup K$. It follows from Theorem 2 that $F(x)=\int_{a}^{x} f d m+F(a)$ for each $x$ in $[a, b]$. That is, $F$ is the Lane integral of a function $f$ of bounded variation on $[a, b]$ with respect to a continuous, increasing function $m$ over $[a, b]$. It should be noted that if $m=I$, then the Lane integral reduces to the Riemann integral so that Theorem 3 contains Riesz's theorem as a special case. 


\section{REFERENCES}

1. F. N. Huggins, Bounded slope variation and the Hellinger integral, Doctoral dissertation, The University of Texas, Austin, 1967.

2. R. E. Lane, The integral of a function with respect to a function, Proc. Amer. Math. Soc., 5 (1954), 59-66.

3. - The integral of a function with respect to a function II, Proc. Amer. Math. Soc., 6 (1955), 392-401.

4. F. Riesz, Sur certains systems singuliers d'équations integrales, Annales de L'École Norm. Sup., Paris, (3) 28 (1911), 33-68.

5. H. L. Smith, On the existence of the Stieltjes integral, Trans. Amer. Math. Soc., 27 (1925), 491-515.

6. J. R. Webb, A Hellinger integral representation for bounded linear functionals, Pacific J. Math., 20 (1967), 327-337.

Recieved November 3, 1970 and in revised form February 17, 1971.

The University of Texas at Arlington 



\title{
PACIFIC JOURNAL OF MATHEMATICS
}

\author{
EDITORS
}

\author{
H. SAMELSON \\ Stanford University \\ Stanford, California 94305 \\ C. R. HOBBY \\ University of Washington \\ Seattle, Washington 98105
}

J. DugundJI

Department of Mathematics

University of Southern California

Los Angeles, California 90007

RICHARD ARENS

University of California

Los Angeles, California 90024

\section{ASSOCIATE EDITORS}
E. F. BeCKenBaCH
B. H. NeUMANN
F. WOLF
K. Yoshida

\section{SUPPORTING INSTITUTIONS}

\author{
UNIVERSITY OF BRITISH COLUMBIA \\ CALIFORNIA INSTITUTE OF TECHNOLOGY \\ UNIVERSITY OF CALIFORNIA \\ MONTANA STATE UNIVERSITY \\ UNIVERSITY OF NEVADA \\ NEW MEXICO STATE UNIVERSITY \\ OREGON STATE UNIVERSITY \\ UNIVERSITY OF OREGON \\ OSAKA UNIVERSITY
}

\author{
UNIVERSITY OF SOUTHERN CALIFORNIA \\ STANFORD UNIVERSITY \\ UNIVERSITY OF TOKYO \\ UNIVERSITY OF UTAH \\ WASHINGTON STATE UNIVERSITY \\ UNIVERSITY OF WASHINGTON \\ AMERICAN MATHEMATICAL SOCIETY \\ NAVAL WEAPONS CENTER
}

The Supporting Institutions listed above contribute to the cost of publication of this Journal, but they are not owners or publishers and have no responsibility for its content or policies.

Mathematical papers intended for publication in the Pacific Journal of Mathematics should be in typed form or offset-reproduced, (not dittoed), double spaced with large margins. Underline Greek letters in red, German in green, and script in blue. The first paragraph or two must be capable of being used separately as a synopsis of the entire paper. The editorial "we" must not be used in the synopsis, and items of the bibliography should not be cited there unless absolutely necessary, in which case they must be identified by author and Journal, rather than by item number. Manuscripts, in duplicate if possible, may be sent to any one of the four editors. Please classify according to the scheme of Math. Rev. Index to Vol. 39. All other communications to the editors should be addressed to the managing editor, Richard Arens, University of California, Los Angeles, California, 90024.

50 reprints are provided free for each article; additional copies may be obtained at cost in multiples of 50 .

The Pacific Journal of Mathematics is published monthly. Effective with Volume 16 the price per volume (3 numbers) is $\$ 8.00$; single issues, $\$ 3.00$. Special price for current issues to individual faculty members of supporting institutions and to individual members of the American Mathematical Society: $\$ 4.00$ per volume; single issues $\$ 1.50$. Back numbers are available.

Subscriptions, orders for back numbers, and changes of address should be sent to Pacific Journal of Mathematics, 103 Highland Boulevard, Berkeley, California, 94708.

PUBLISHED BY PACIFIC JOURNAL OF MATHEMATICS, A NON-PROFIT CORPORATION

Printed at Kokusai Bunken Insatsusha (International Academic Printing Co., Ltd.), 270, 3chome Totsuka-cho, Shinjuku-ku, Tokyo 160, Japan. 


\section{Pacific Journal of Mathematics}

\section{Vol. 39, No. $3 \quad$ July, 1971}

William O'Bannon Alltop, 5-designs in affine spaces ................... 547

B. G. Basmaji, Real-valued characters of metacyclic groups ................. 553

Miroslav Benda, On saturated reduced products....................... 557

J. T. Borrego, Haskell Cohen and Esmond Ernest Devun, Uniquely representable semigroups. II.......................................

George Lee Cain Jr. and Mohammed Zuhair Zaki Nashed, Fixed points and stability for a sum of two operators in locally convex spaces ....................

Donald Richard Chalice, Restrictions of Banach function spaces ...............

Eugene Frank Cornelius, Jr., A generalization of separable groups ..............

Joel L. Cunningham, Primes in products of rings ......................

Robert Alan Morris, On the Brauer group of $Z$.

593

603

615

David Earl Dobbs, Amitsur cohomology of algebraic number rings ...............

Charles F. Dunkl and Donald Edward Ramirez, Fourier-Stieltjes transforms and

weakly almost periodic functionals for compact groups ...................

Hicham Fakhoury, Structures uniformes faibles sur une classe de cônes et

d'ensembles convexes ......................................

Leslie R. Fletcher, A note on C $\theta \theta$-groups.

Humphrey Sek-Ching Fong and Louis Sucheston, On the ratio ergodic theorem for

semi-groups............................................

James Arthur Gerhard, Subdirectly irreducible idempotent semigroups ...........

Thomas Eric Hall, Orthodox semigroups.....................

Marcel Herzog, $C \theta \theta$-groups involving no Suzuki groups ..........

669

687

John Walter Hinrichsen, Concerning web-like continua ..........

691

Frank Norris Huggins, A generalization of a theorem of F. Riesz.

695

Carlos Johnson, Jr., On certain poset and semilattice homomorphisms

703

Alan Leslie Lambert, Strictly cyclic operator algebras ...........

717

Howard Wilson Lambert, Planar surfaces in knot manifolds . . .

727

Robert Allen McCoy, Groups of homeomorphisms of normed linear spaces ....... 735

T. S. Nanjundiah, Refinements of Wallis's estimate and their generalizations ...... 745

Roger David Nussbaum, A geometric approach to the fixed point index .......... 751

John Emanuel de Pillis, Convexity properties of a generalized numerical range .... 767

Donald C. Ramsey, Generating monomials for finite semigroups ....

783

William T. Reid, A disconjugacy criterion for higher order linear vector differential equations...

Roger Allen Wiegand, Modules over universal regular rings...

Kung-Wei Yang, Compact functors in categories of non-archimedean Banach

spaces.

R. Grant Woods, Correction to: "Co-absolutes of remainders of Stone-Čech compactifications".

Ronald Owen Fulp, Correction to: "Tensor and torsion products of

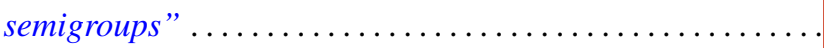

Bruce Alan Barnes, Correction to: "Banach algebras which are ideals in a banach 